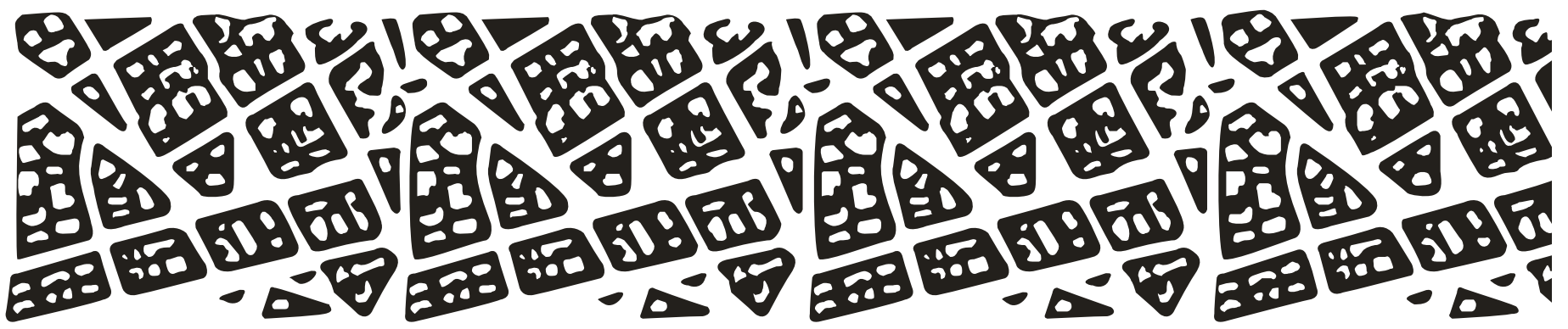

\title{
Arte e destruição
}

Kelvin Falcão Klein

\section{Resumo}

O objetivo deste ensaio é refletir sobre o papel da cidade e de suas margens e periferias em momentos específicos das obras de três escritores contemporâneos: o norte-americano William T. Vollmann, o chileno Roberto Bolaño e o alemão W. G. Sebald. Dando base ao cenário da análise estão questões como a violência enquanto formadora de fronteiras; o pertencimento (comunidade) como corolário dos projetos totalitários e o posicionamento possível da ficção diante disso.

Palavras-chave: literatura contemporânea; violência; totalitarismo.

\section{Abstract}

The purpose of this essay is to reflect on the role of the city and its margins and peripheries at specific fictional works of three contemporary writers: the American William T. Vollmann, the Chilean Roberto Bolaño and the German W. G. Sebald. Giving rise to the scenario analysis are issues such as violence while forming borders, the belonging (community) as a corollary of the totalitarian projects and possible placement of fiction before that.

Keywords: contemporary literature; violence; totalitarianism. 
Arte e destruição andam juntas no percurso que se inicia, e que se espalha pelas fronteiras tênues das cidades - arte como instrumento, passagem, umbral ou justificativa para a destruição e a violência. Há uma cena inaugural, banal em sua naturalidade e circulação: a queda das muralhas de Jericó. O sexto capítulo do livro de Josué, no Antigo Testamento, nos fala da cidade e de seu perímetro, sua periferia, seu limiar, ou seja, a muralha. O povo que se anunciava escolhido, detentor também da voz do relato, estabelece um sítio ao redor da cidade, reclamando aquilo que, da noite para o dia, passa a ser seu. Os mais hábeis músicos da comunidade tocaram seus instrumentos ao longo de dias, enquanto todos davam voltas ao redor da muralha, que, em determinado momento, desmoronou. As extremidades da cidade agora guardavam centenas de cadáveres, funcionando como um cemitério circular, e os que sobreviveram foram queimados junto com suas posses; crianças, mulheres, homens e animais, junto com todo o resto das construções. Toda prata e todo ouro foram recolhidos. A área estava agora ocupada e sua população dizimada.

Essa violência já está costurada ao imaginário ocidental judaico-cristão, sendo difundida sem questionamento e, por vezes, sem contextualização, pelo simples fato de estar na Bíblia. Tomada muitas vezes como lição de persistência e como metáfora para as "barreiras" que a vida coloca no caminho dos indivíduos, a passagem referida promove uma problematização sobre o espaço da cidade e de suas fronteiras, e sobrevive, em chave de intertextualidade, em momentos sutis da literatura contemporânea. "Nunca há um documento da cultura que não seja, ao mesmo tempo, um documento da barbárie", escreveu Walter Benjamin ${ }^{1}$, e visitando obras como as de Roberto Bolaño, W.G. Sebald e William T. Vollmann, é possível se perder com um pouco mais de densidade na indecidibilidade que atua entre a arte e a destruição, que nos levará de Jericó até o deserto mexicano de Sonora, com uma silenciosa passagem pelas ruínas alemãs do pós-guerra.

Em 1997, o escritor alemão W.G. Sebald² deu uma série de palestras na cidade de Zurique, que mais tarde foram reunidas em livro sob o título Sobre a história natural da destruição $o^{3}$. Suas leituras versavam sobre guerra aérea e literatura, e exploravam o tema silenciado da destruição da Alemanha durante a II Guerra Mundial. Sebald argumenta que a literatura alemã do pós-guerra, e a população de forma geral, obliteraram o próprio passado, desviando a mirada, abafando a angústia e camuflando os sintomas. Os dados são expressivos: um milhão de toneladas de bombas sobre 131 cidades (muitas delas despejadas quando o cerco já estava rompido, em lugares nos quais o exército do Reich não estava sequer presente); 600.000 civis mortos (mais baixas civis do que de todos os aliados somados); sete milhões e meio de desalojados. Sebald salienta, e esse é o ponto que lhe parece mais dolorido em sua retrospecção, que a memória alemã (tanto popular quanto literária) absorveu esse trauma como uma pena merecida, silenciando

1 LÖWY, Michael. Walter Benjamin: Aviso de incêndio. Uma leitura das teses "Sobre o conceito de história". Tradução de Jeanne Marie Gagnebin e Marcos Lutz-Müller. São Paulo: Boitempo, 2005, p. 70.

2 Nas páginas desta mesma revista, anos atrás, Silviano Santiago declarou: "Gostaria de ter mais tempo para ler mais e melhor os livros de W.G. Sebald”. In: SANTIAGO, Silviano. Entre miradas. Outra travessia. Florianópolis, n. 3, 2. semestre de 2004, p. 13.

3 Consultei a tradução para o inglês: SEBALD, W.G.. On the natural bistory of destruction. Tradução Anthea Bell. Nova Iorque: Random House, 2003 
sobre seus efeitos e seguindo em frente sem trabalhar o trauma.

Não há dúvida que muitos fantasmas nascem disso e a partir daí retornam. Daniel Link, em publicação recente, destaca a presença e a produtividade desses espectros ao longo da produção artística do presente. Em sua leitura,

Los fantasmas tienen su potencia y esa potencia es una fuerza de desintegración. Si hay una potencia de ser en los fantasmas es porque estos se mueven en el desierto (o páramo) como a través de un espacio agujereado: son la pura potencia del ser (o del no ser), nunca un límite, siempre un umbral ${ }^{4}$.

Retiro duas ideias dessa citação, que permanecerão nos exemplos que escolho: o fantasma que se movimenta no deserto (fundamental para Bolaño e Vollmann) e sua característica de ser sem-limite, como uma passagem, um limiar, uma "força de desintegração". Se narrar o trauma é sempre um desejo de renascer, como aponta Marcio Seligmann-Silva ${ }^{5}$, silenciar o trauma pode ser encarado como desejo de permanecer morrendo. $\mathrm{O}$ trauma encontra na narração um meio para sua imaginação, para a construção de suas imagens e figuras - seus espectros, seus fantasmas.

Podemos perguntar, partindo de Sebald e tendo como fundo a narração como elaboração do trauma: por que questionar a destruição alemã, depois de tantos anos? O movimento mais fácil é deixar de lado a ambiguidade e compreender o contexto como algo merecido, afinal de contas, não foi o Holocausto a maior de todas as violências, fora de qualquer estruturação possível para a violência? A simples menção a essa partícula de indecidibilidade basta para abrir a história.

É o que temos, por exemplo, em La Literatura Nazi en América ${ }^{6}$, livro que o escritor chileno Roberto Bolaño publica em 1996. À maneira da Historia universal de la infamia, de Borges, realiza um inventário de figuras mescladas, nem documento, nem ficção. Uma particularidade reúne as figuras criadas por Bolaño: todos nascidos nas Américas, todos literatos e todos simpatizantes de ideias nazi-fascistas. Como pode um artista, um poeta, alguém que se pretende ligado à criação do belo e à divulgação do bom espírito, compactuar com um sistema de pensamento tão nefasto? É possível compactuar de forma indireta ou inconsciente a esse sistema de pensamento, sem necessariamente ter de pegar em armas, assassinar pessoas e gerenciar campos de concentração? O silêncio, a ignorância autoimposta ou a passividade seriam indícios de uma participação enviesada do homem cotidiano no extermínio? O silêncio, além de uma negação, é uma possibilidade de se matar novamente as vítimas, simbolicamente. Este é o outro lado do trauma silenciado.

Outro ponto doloroso que Bolaño desenvolve: a ética nazi-fascista, se for possível denominar algo assim, não se encerra com a segunda bomba atômica sobre o Japão, aquela que encerra a II Guerra Mundial; a ética nazi-fascista desdobra-se sobre a

4 LINK, Daniel. Fantasmas: imaginación y sociedad. Buenos Aires, Eterna Cadencia, 2009, p. 13. Uma discussão que, em larga medida, está baseada em Giorgio Agamben, Estâncias: a palavra e o fantasma na cultura ocidental. Tradução Selvino José Assmann. Belo Horizonte: Editora UFMG, 2007.

5 SELIGMANN-SILVA, Márcio. Narrar o trauma: escrituras híbridas das catástrofes. Gragoatá. Niterói, n. 24, p. 101-117, 1. sem. 2008, p. 102.

6 BOLAÑO, Roberto. La literatura nazi em América. Buenos Aires: Seix Barral, 1996. 
América Latina7 ${ }^{7}$ Este é o solo sob o qual ela germinará, depois de ter sido afogada com um milhão de toneladas de bombas na Europa. Esse contexto ainda obscuro sobrevive no tempo, dobrado sobre si, adquirindo feições sintomáticas distintas a cada esforço de memória ou de apropriação que é realizado em sua direção.

Tomemos La Literatura Nazi en América como um inventário, uma enciclopédia manca, um almanaque do absurdo. A premissa é a seguinte: proliferaram nas Américas escritores de feições estéticas nazi-fascistas. Não que tenham efetivamente matado pessoas e/ou incinerado seus corpos (ainda que alguns tenham cometido, sim, coisas semelhantes). Não: cultivam posicionamentos ideológicos nazi-fascistas, que aparecem, junto com temas racistas e/ou eugenistas, por exemplo, em suas ficções. Um delicado arranjo entre ética e estética, que Roberto Bolaño elabora em chave irônica enquanto revisita, intertextualmente, tanto a história contemporânea quanto uma variedade de gêneros literários.

Se ampliarmos a perspectiva para outros livros do escritor chileno, encontraremos ilustrações interessantes desse cenário. Em $2666^{8}$, romance póstumo de Roberto Bolaño, há uma cena na qual os críticos literários, retratados na primeira parte do romance (que são, os quatro, especialistas em Arcimboldi, o escritor alemão que motiva as 1.119 páginas do romance), estão em um táxi, que é dirigido por um paquistanês. O motorista, em determinado momento, é ríspido ou não entende o que eles querem. O táxi para e os críticos literários começam a espancar violentamente o motorista (que usava um turbante, inclusive). Uma cena cômica e brutal, da mesma forma que certas figuras de Literatura Nazi. Indecidibilidade entre ironia e denúncia. Ser um esteta não salva você de ser um monstro. Uma coisa não anula a outra. Em certos momentos da história, parece anunciar Bolaño, uma coisa pressupõe a outra. Os críticos distribuem socos dizendo ao taxista: este é por Salman Rushdie, este é pelas feministas', como se rotulassem a violência ou o pertencimento da comunidade como motivo para a violência.

O tom é outro, por exemplo, na cena de Noturno do Chile ${ }^{10}$ (novela de Bolaño já traduzida no Brasil) que mostra um sujeito torturado em um quartinho subterrâneo, durante a ditadura militar, enquanto, no andar de cima, o casal dono da casa organiza encontros literários (para identificar os subversivos de maneira mais cirúrgica). A ironia não toma parte nesse contexto, mas o debate e o anúncio persistem: para cada tertúlia no andar de cima, há uma tortura no andar de baixo. Ética e estética estão irremediavelmente ligadas, não se pensa a possibilidade de dizer sem pensar a obrigatoriedade de calar, em algum ponto. A arte, invariavelmente, esbarra na destruição. A advertência de

\footnotetext{
7 Em muitas releituras ficcionais da história, as cidades periféricas latino-americanas tornam-se centro nesse reposicionamento político no pós-guerra. Amphitryon, novela escrita pelo mexicano Ignacio Padilla, trabalha ficcionalmente com o projeto nazista de recrutamento de sósias, que efetivamente aconteceu para prevenção de atentados aos principais nomes do Reich. Padilla também explora o exílio argentino de Adolf Eichmann, o idealizador dos campos de concentração. Jorge Volpi, também mexicano, publica, em 1999, En busca de Klingsor, uma apropriação ficcional dos experimentos científicos nazistas durante a II Guerra. Dentro do mesmo cenário, temos, em 2003, o lançamento da "Operação: Última Chance", desenvolvida pelo Centro Simon Wiesenthal, de Israel, visando à captura de nazistas foragidos ainda vivos. O alvo principal era Aribert Heim, também conhecido como "Dr. Morte”, responsável por uma série de experimentos e torturas nos campos. Informações indicavam que Heim estava escondido em Paysandú, no Uruguai. Em 2007, a Operação chegou à América Latina. Outro dado sobre Heim diz que viveu na ilha espanhola de Ibiza, em uma colônia de nazistas criada por Franco, nos anos 60.

8 BOLAÑO, Roberto. 2666. Barcelona: Anagrama, 2006.

9 Ibidem, p. 103

10 BOLAÑO, Roberto. Noturno do Chile. Tradução Eduardo Brandão. São Paulo: Cia. das Letras, 2004
} 
Walter Benjamin sobre o contato da cultura com a barbárie condensa todo o percurso e se anuncia ininterruptamente.

Noturno do Chile é um romance curto narrado por um padre, um extenso monólogo dividido em dois parágrafos, sendo que o segundo consta de apenas uma frase, justamente a frase final do livro. Sebastián Urrutia Lacroix, o padre, é também crítico literário, e narra suas memórias de juventude, vivida durante a ditadura de Pinochet. Por suas inclinações literárias, entra em contato com artistas e entusiastas - inclusive com o homem que vê o corpo torturado no porão da casa, e que faz o padre Lacroix nunca mais retornar ao local por conta disso. Seu olhar incrédulo e por vezes ingênuo observa de perto muitas particularidades angustiantes do período repressivo no Chile (o padre chega inclusive a ser convocado para dar aulas sobre marxismo a Pinochet e parte de seus oficiais de elite).

2666, por outro lado, é extremamente longo. Lançado em 2006, três anos após a morte de Bolaño, o romance tem mais de mil páginas. De forma grosseiramente sucinta, é possível afirmar que o livro é composto por dois tópicos principais: a vida e a obra do escritor alemão Benno von Archimboldi (pseudônimo de Hans Reiter) e os assassinatos de mulheres ocorridos em Ciudad Juarez, no México, mais especificamente na área do deserto de Sonora. Desde 1993, mulheres vem sendo assassinadas em Ciudad Juarez, e a grande maioria dos casos permanece, até hoje, sem solução. Bolaño constrói boa parte de seu romance (especialmente o capítulo denominado "La parte de los crímenes") em torno desse fato real que ainda está em processo. A trama nos diz que Archimboldi foi soldado alemão durante a II Guerra, época na qual começou a escrever. Um de seus sobrinhos, que mora no México, é acusado, muitos anos depois, de ser um dos responsáveis pelos assassinatos das mulheres. Os críticos literários (são quatro: um italiano, um francês, um espanhol e uma inglesa) que espancaram o taxista são especialistas na obra de Archimboldi, e também viajam ao México. Com essas figuras, e outras que vão sendo agregadas ao panorama, Bolaño costura 2666, que parece não ter fim, tantas são as frentes que abraça (da mesma forma que abraça a impossibilidade inerente à sua realização).

$\mathrm{Na}$ frase final de 2666, "Poco después salió del parque y a la mañana siguiente se marchó a México" ${ }^{11}$, Bolaño une definitivamente o imaginário bélico nazi-fascista com a América Latina, pois é o momento no qual Archimboldi, ao saber que seu sobrinho está do outro lado do oceano, parte para o México. Esse é o projeto de Literatura Nazi, que atinge o ápice em 2666. A parte dos crimes em Ciudad Juarez, centenas e centenas de mulheres mortas ao longo de 10, 15 anos, é a versão latino-americana dos campos de concentração. $O$ deslocamento de Archimboldi para o México (que não acompanhamos, porque o romance acabou) é o nó final de uma trama minuciosamente arquitetada para mostrar que o Extermínio ainda está acontecendo, ainda está passando, re-configurado em uma matriz hispano-hablante. Este é o local ideal, Bolaño segue anunciando, para que a barbárie floresça - amalgamada com a cultura, com o beletrismo, com a ignorância cultivada, com o senso comum travestido de europeísmos.

De forma nunca declarada ou precisa, os fantasmas circulam por 2666 - ora tomando as feições das mulheres assassinadas em Ciudad Juarez, ora tomando as feições

11 BOLAÑO, Roberto. 2666. Barcelona: Anagrama, 2006, p. 1119. 
dos judeus exterminados durante a II Guerra Mundial. Sebald nos fala da destruição nas cidades europeias, do amontoado de destroços que se tornou a Alemanha após os bombardeios e o silêncio que decorreu disso, além de sublinhar a dificuldade que os escritores alemães do pós-guerra encontram para trabalhar esses traumas em suas ficções. Bolaño apresenta os destroços mexicanos - e os cadáveres que se amontoam na periferia do deserto. La Literatura Nazi en América mostra como o fantasma nazi-fascista deslizou para a América Latina. 2666 retoma a tarefa e particulariza a questão na figura do escritor alemão Benno von Archimboldi, que, como ficamos sabendo na parte do romance dedicada exclusivamente a ele, ajudou na eliminação de centenas de judeus. Sua relação com os crimes de Ciudad Juarez nunca fica clara, como vimos a partir da frase final do livro, mas é possível observar como sua figura atualiza o cenário totalitário europeu em solo mexicano. Ao escrever um romance com mais de mil páginas, que, em sua frase final, consegue ainda demandar uma continuidade (que quase se impõe para a crítica), Roberto Bolaño exemplifica a incompletude radical de um possível projeto da modernidade, que titubeia em seus paradoxos e contrassensos. E esse cenário fica condensado na permanente oscilação entre arte e destruição que sua obra encena.

Giorgio Agamben, em fala proferida durante um seminário sobre Georges Bataille, realizado em Roma em 1986 (cuja tradução foi publicada em Outra travessia), conta de seu encontro com Pierre Klossowski, a quem procurou para saber melhor dos encontros deste último com Walter Benjamin. Klossowski diz a Agamben que, ao mencionar Bataille, Benjamin teria dado o seguinte diagnóstico: "Vous travaillez pour le fascisme!"’12. A dúvida de Agamben segue a seguinte linha: como Benjamin pôde identificar o fascismo em uma obra, a de Bataille, marcada pela ruptura, pela fuga do senso comum, por um contato extremo com a morte e a liberdade da morte, uma obra acefálica - ou seja, marcada pelo questionamento ao poder estabelecido e instalada no interior de uma crítica a todo tipo de coerção ou mordaça ao desejo?

Agamben deixa a questão em aberto (lança para o futuro, convoca o futuro, como faz Bolaño, desde o título: 2666), e identifica na advertência de Benjamin o diagnóstico de certo "destino totalitário do ocidente"13, que, como visto, também é diagnosticado por Roberto Bolaño em sua ficção. Não se trata de uma falsa polêmica entre Bataille e Benjamin, mas de uma arqueologia que se desvia para o presente e pensa a sobrevivência de problemas éticos enunciados 60,70 anos atrás. As forças não são inerentes aos nomes, pois circulam e operam em metamorfose.

Philippe Lacoue-Labarthe e Jean-Luc Nancy escrevem, juntos, O mito nazista. Em determinado ponto do artigo, mencionam a seguinte reflexão sobre a clivagem que ocorre entre o nome e a força, que nos interessa sobremaneira:

Existe um abismo entre uma tradição de pensamento e a ideologia que vem, sempre de modo abusivo, inscrever-se sobre ela. $\mathrm{O}$ nazismo não está mais em Kant, em Fichte, em Hölderlin ou em

\footnotetext{
12 AGAMBEN, Giorgio. Bataille e o paradoxo da soberania. Tradução Nilcéia Valdati. Outra travessia. Florianópolis, $\mathrm{n}^{\circ}$ $5,2^{\circ}$ semestre de 2005 , p. 91

13 Ibidem, p. 93.
} 
Nietzsche (todos pensadores solicitados pelo nazismo) - ele não está mesmo, no limite, mais no músico Wagner - do que o Gulag está em Hegel ou em Marx. (...) Deve-se condenar apenas o pensamento que se coloca deliberadamente (ou confusamente, emocionalmente) a serviço de uma ideologia e abriga-se atrás dela ou procura aproveitar da sua potência: Heidegger durante os primeiros dez meses do nazismo, Céline sob a Ocupação e um bom número de outros, nessa época ou desde então (e em outros lugares). ${ }^{14}$

A partir daí, uma imensidade de questões se coloca. Para os fins deste ensaio, e para canalizar em direção à leitura tanto de Bolaño quanto de Vollmann, que virá em seguida, destaco esquematicamente as seguintes: o problema do pertencimento, da comunidade, do fantasma do total, da totalização, das grandes empresas coletivas, dos grandes projetos, o problema de reunir-se ao redor de um nome e a partir dele estabelecer verdades, dogmas, sistemas fixos e estruturas rijas de vivência. Ou seja, inscrever-se sobre os discursos, como escrevem Nancy e Lacoue-Labarthe. O "nome" em questão pode ser o nome do sujeito, o nome da nação, o nome da ideia, um nome que atravessa, suplanta e ultrapassa todo sujeito que com ele se relaciona.

William T. Vollmann ${ }^{15}$, escritor norte-americano nascido em 1959, publicou Imperial, um extenso volume que mescla narrativa, relato jornalístico, estudo sociológico e mais uma porção de outras possibilidades, no ano de $2009^{16}$ - excelente exemplo, portanto, dessa possibilidade de reunião em torno de uma coletividade, comunidade e projeto, ou seja, o próprio Império que subjaz ao título. Em suas mais de 1.300 páginas, Imperial carrega o fardo de uma obsessão: a tentativa de saturar a compreensão impossível daquilo que acontece ao longo de uma faixa de terra, um perímetro, uma periferia muito bem delimitada. Trata-se de um trecho da fronteira do México com os Estados Unidos da América (não mais que 140 quilômetros), um ponto privilegiado para a observação de uma ferida aberta. Imperial é essa faixa de terra, que apresentava, no lado norte-americano, abundância, e, no lado mexicano, desertificação. Na virada do século, graças a projetos de irrigação, o lado norte-americano floresceu: alface, algodão, melões e aspargos. Os efeitos colaterais foram para o outro lado: rio envenenado, terra saturada, deserto. A terra foi abandonada assim que se esgotou, deixando desemprego e violência como resquício.

Vollmann passou anos pesquisando e observando a área, vivendo entre os trabalhadores ilegais, fumando crack com prostitutas, acompanhando as transformações

14 LACOUE-LABARTHE, Philippe; NANCY, Jean-Luc. O mito nazista. Tradução Márcio Seligmann-Silva. São Paulo: Iluminuras, 2002, p. 28.

15 Além de Imperial, Vollmann (figura controversa do cenário literário norte-americano) é responsável por outros volumes ainda mais extensos, que também tratam da violência nas periferias das cidades e das consequências disso sobre os indivíduos. Em 2004, publica Rising Up and Rising Down, um tratado que procura dissecar causas e efeitos da violência que levou 20 anos para ser realizado. São sete volumes e mais de 3 mil páginas, com fotografias e ilustrações de apoio. Vollmann, ao longo de sua pesquisa para o livro, morou no Camboja, na Somália e no Iraque. Europe Central, de 2005, vencedor do National Book Award, é, como Imperial, um livro híbrido, que retrata o trânsito de vários personagens exilados e desterrados, andando a esmo pelas fronteiras difusas da Europa desde a II Guerra. Foca principalmente sobre as consequências dos regimes totalitários da Alemanha e da União Soviética, tomando como personagens muitos dentre aqueles sete milhões de desalojados de que fala Sebald na conferência que menciono no início deste ensaio. Para 2010, Vollmann prepara um livro sobre o aborto (The Shame of Our Youth) e outro sobre casos de estupro.

16 VOLLMANN, William T. Imperial. New York, Viking, 2009. 
na fronteira e nos corpos arrojados no vazio desse limiar - expondo seu próprio corpo ao projeto estético que promovia, ou seja, entrelaçando uma ética, um posicionamento de vida, com a estética que lhe determina, social e historicamente. O projeto de Imperial é análogo ao de Roberto Bolaño em 2666. São duas obras fora de proporção, exaustivas, estafantes, exigentes, de difícil leitura, publicação e, consequentemente, de difícil venda - obras anti-mercadológicas, até certo ponto -, que arriscam a própria integridade no percurso que oferecem. Os dois livros visitam as fábricas (maquiladoras) do deserto mexicano, atrás das imagens que condensam os traumas dessa linha limítrofe do real, onde a narração delira em conjunto com seu objeto ausente. São dois retratos de uma mesma terra devastada: com Bolaño, vemos que revolvendo e escavando esse espaço encontram-se os cadáveres das mulheres assassinadas; com Vollmann, vemos que na superfície, palmilhando o deserto, cruzando a fronteira, estão os sujeitos invisíveis, os fantasmas, as testemunhas. Esse é o ambiente que também capta, mais de cinquenta anos antes, Cesare Pavese, na passagem de $A$ lua e as fogueiras em que o narrador relembra sua passagem pelo deserto mexicano (o mesmo deserto de Vollmann e Bolaño):

Agora eu pensava que por mais que os californianos fossem gente esperta, aqueles quatro mexicanos andrajosos faziam algo que nenhum deles seria capaz de fazer. Acampar e dormir naquele deserto, mulheres e crianças, naquele deserto que era a casa deles, onde deviam se entender até com as cobras. ${ }^{17}$

Vê-se que todo trauma gera uma zona de cegueira, que se espalha no tempo e no espaço. Trata-se de uma lacuna que se abre no processo do trauma, trabalhada pela ficção a partir da sobreposição de temporalidades que a narração evidencia e expande como forma essencial do trauma. As coisas não vão simplesmente por terra, elas deslizam, escapam, sobrevivem: a terra alemã bombardeada de Sebald penetra no deserto de Sonora de Bolaño, assim como o verde norte-americano opressivo de outrora, que Vollmann nos lembra, sobrevive na desolação do lado mexicano da fronteira.

As obras de ficção tocadas neste ensaio, de Bolaño e Vollmann, além de evocar fantasmas e os traumas a eles atrelados (que geram, por sua vez, narração) dão testemunho daquilo que Agamben denomina o "destino totalitário do ocidente", e o fazem desde a forma até o conteúdo: volumes extensos que procuram abarcar inúmeras vidas e destinos, mas que também tem a consciência de que a empresa é fracassada de antemão. Tudo está em 2666, mas, ainda assim, há margem para a incompletude quando a última frase é enunciada; tudo está em Imperial, mas, ainda assim, Vollmann consegue destrinchar a barbárie contemporânea por um novo viés a cada volume que publica. A casa (nação, comunidade, coletividade) é sempre de alguém que está alhures, como afirma Pavese ao dizer que o deserto (Ciudad Juarez, Imperial, a periferia radical) era a casa dos "quatro mexicanos andrajosos". Ou seja, a violência sempre opera a partir de uma lógica do pertencimento, da anexação e da totalização.

Observar, nos textos literários do presente, como as periferias das cidades foram atacadas, deixadas de lado, postas em evidência, transportadas através do tempo e do espaço, postas no centro e em seguida descentradas, reivindicadas e reinscritas

17 PAVESE, Cesare. A lua e as fogueiras. Tradução Liliana Laganá. São Paulo: Berlendis \& Vertecchia, 2002, p. 71. 
na história: essa é a complicação autoimposta que este ensaio procurou problematizar. Assim como o ficcionista em sua escritura e pesquisa, o crítico, em sua leitura, em sua tomada de posição, procura sempre inserir-se em outros lugares, outros tempos, por vezes de forma simultânea.

Certa crítica literária do presente, portanto, busca ler os dados perdidos nos interstícios dos textos, como Jericó e sua violência, como as bombas sobre a Alemanha e sua gratuidade, que funcionam como a carta roubada de Poe: quanto mais aparece, mais é invisível (porque desconfortável). Como são os mexicanos na fronteira de Vollmann e os cadáveres no deserto de Sonora, que Bolaño convoca para aumentar o desconforto cognitivo daquilo que é imediato, que se mostra enquanto acontece.

Trata-se, enfim, por parte da leitura crítica, de um procedimento de corte e montagem, de preparação de um cenário propício para a queda abrupta do sentido para o tropeço, a falha, a gagueira e o tartamudeio que se insinua nas malhas da história. Ou seja, abandonar elementos díspares (Bolaño, Sebald e Vollmann, por exemplo) no interior de um abismo e, manejando uma lanterna que funciona de forma errática e intermitente, procurar obter breves clarões no delírio.

\section{Referências bibliográficas}

AGAMBEN, Giorgio. Estâncias: a palavra e o fantasma na cultura ocidental. Tradução Selvino José Assmann. Belo Horizonte: Editora UFMG, 2007. . Bataille e o paradoxo da soberania. Tradução Nilcéia Valdati. Outra

travessia. Florianópolis, $\mathrm{n}^{0} 5,2^{\circ}$ semestre de 2005, p. 90-93.

BOLAÑO, Roberto. 2666. Barcelona: Anagrama, 2006.

Letras, 2004 . . Noturno do Chile. Tradução Eduardo Brandão. São Paulo: Cia. das . La literatura nazi en América. Buenos Aires: Seix Barral, 1996.

LACOUE-LABARTHE, Philippe; NANCY, Jean-Luc. O mito nazista. Tradução Márcio Seligmann-Silva. São Paulo: Iluminuras, 2002.

LINK, Daniel. Fantasmas: imaginación y sociedad. Buenos Aires, Eterna Cadencia, 2009.

LÖWY, Michael. Walter Benjamin: Aviso de incêndio. Uma leitura das teses "Sobre o conceito de história". Tradução Jeanne Marie Gagnebin e Marcos Lutz-Müller. São Paulo: Boitempo, 2005.

SANTIAGO, Silviano. Entre miradas. Outra travessia. Florianópolis, $\mathrm{n}^{0} 3,2^{\circ}$ semestre de 2004 .

SEBALD, W.G.. On the natural history of destruction. Tradução Anthea Bell. Nova Iorque: Random House, 2003.

SELIGMANN-SILVA, Márcio. Narrar o trauma: escrituras híbridas das catástrofes. Gragoatá. Niterói, n. 24, p. 101-117, 1. sem. 2008.

PAVESE, Cesare. A lua e as fogueiras. Tradução Liliana Laganá. São Paulo: Berlendis \& Vertecchia, 2002.

VOLLMANN, William T. Imperial. New York, Viking, 2009. 